\title{
Effect of Langmuir Monolayer of Bovine Serum Albumin Protein on the Morphology of Calcium Carbonate
}

\author{
Zhonghui Xue ${ }^{1 *}$, Ning Xue ${ }^{2}$ \\ ${ }^{1}$ Shanghai Publishing and Printing College, Shanghai, China \\ ${ }^{2}$ Northeastern University, Qinhuangdao, China \\ Email: ^hnlgxzh@163.com
}

How to cite this paper: Xue, Z.H. and Xue, N. (2020) Effect of Langmuir Monolayer of Bovine Serum Albumin Protein on the Morphology of Calcium Carbonate. Open Access Library Journal, 7: e5796. https://doi.org/10.4236/oalib.1105796

Received: September 17, 2019

Accepted: May 29, 2020

Published: June 2, 2020

Copyright $\odot 2020$ by author(s) and Open Access Library Inc.

This work is licensed under the Creative Commons Attribution International License (CC BY 4.0).

http://creativecommons.org/licenses/by/4.0/ (c) (i) Open Access

\begin{abstract}
In this paper we used BSA Langmuir monolayer as templates to study the effect of solute concentration on regulated biomineralization of calcium carbonate. During the crystallization process, it is found that the morphology of the calcium carbonate can be strongly affected by the solute concentration in presence of BSA Langmuir monolayer. X-ray Diffraction (XRD) results show that the crystal of calcium carbonate formed is all the calcite phase with a higher orientation. SEM images show that the morphology of calcite is time-dependent at different solute concentrations. The effect of solute concentration on morphology was discussed and the interaction of particles with bovine serum albumin Langmuir monolayers was proposed.
\end{abstract}

\section{Subject Areas \\ Composite Material}

\section{Keywords}

Bovine Serum Albumin Protein

\section{Introduction}

In nature, biomineralization applies natural proteins to control and direct the crystallization of biominerals such as calcium carbonate with special orientation, texture, and morphology at ambient conditions [1] [2]. Inspired by the formation of biominerals, a variety of mimetic methodologies have been designed and carried out to investigate the possible mechanism of the formation of natural biominerals [3]. Also, following the idea of protein directed biomineralization, 
many other soluble organic templates such as amino acids [4], polycarboxylic acids [5], synthetic peptides [6], and dendrimers [7] are applied to control the mineralization process in vivo. In recent years, based on the fact that the biomineralized materials often contain proteins that are rich in glutamic or aspartic acid residues, proteins have been successfully developed to control the mineralization process of calcium carbonate in solution and have helped to produce a variety of materials with novel microstructures [8] [9] [10] [11] [11].

Biominerals (e.g. shells and bones) are made up of inorganic single crystals intergrown with organic material, and the crystals often show a remarkable degree of preferential alignment. What can we learn about interface nucleation by mimicking their methods? It is known that when biominerals are deposited, a locally supersaturated solution is first generated by the organism near the organic surface. Thus, one can simulate the process by making supersaturated solutions, putting them in contact with a suitable bioorganic surface, and seeing what happens. Langmuir monolayers are excellent for this purpose: they are already in contact with water, they are ordered, and their structures are in many cases well-known and can be varied by changing pressure, temperature, etc. There have been a number of studies of nucleation under Langmuir monolayers. Mann and coworkers have performed extensive studies of the nucleation of calcium carbonate [12] [13], barium sulfate [14], etc., showing that crystals will nucleate preferentially under the organic monolayer. They grow as specific polymorphs (when there is a choice, such as calcite/aragonite/vaterite) and have specific lattice orientations, depending on the monolayer material and on parameters such as temperature, monolayer pressure and subphase $\mathrm{pH}$. Zhao et al. [15] have grown oriented crystals of lead sulfide by exposing lead nitrate solutions to hydrogen sulfide gas; Tang et al. [16] have grown copper sulfate.

The mechanistic understanding of additive controlled mineralization is still lacking. Weiner and Traub have proposed an epitaxial model for aragonite formation in nacre with distinct 001 orientation [17] [18]. Volkmer et al. demonstrated that it is not the epitaxial match but the charge density that plays a key role in the oriented growth of $\mathrm{CaCO}_{3}$ crystals under a monolayer of amphiphilic octaacids [19] [20].

Many studies on the effect of proteins and solute concentration at mixed solution on calcium carbonate crystal growth have been reported recently [21] [22] [23], but little research has been carried out on the cooperative influence of protein Langmuir monolayer and solute concentration on calcium carbonate precipitation.

This paper mainly discusses the influence of solute concentration on calcium carbonate morphology. The aim of these experiments is to exploit a simple method of forming unusual structure by changing the solute concentration. Simultaneously, the possible formation mechanism of $\mathrm{CaCO}_{3}$ crystals on the basis of the principle of biomineralization was discussed. It is significant to understand the mechanism of biomineralization and synthesize new and special functional 
materials.

\section{Experiments}

\subsection{Materials}

Analytical grade $\mathrm{CaCO}_{3}$ was obtained form Institute of Biological Products of Tianjin (Tianjin, China). Analytical grade bovine serum albumin (Sigma, USA) was used in all experiments. BSA contains 582 amino acid residues and has a molecular weight of $67,000 \mathrm{~g} \cdot \mathrm{mol}^{-1}$. It is also well known that it has an isoelectric point at pI 4.7. Amyl alcohol was analytical purity obtained from the (Tianjin Chemicals Co. Ltd). All solutions were prepared with triply deionized water, its conductivity was a resistance of $18 \mathrm{M} \Omega \cdot \mathrm{cm}^{-1}$ and its $\mathrm{pH}$ was 7.0.

The preparation of the protein Langmuir monolayer was performed using a commercial LB trough (KSV50003, Finland) at room temperature. The pressure/area isotherms were recorded using a computer-controlled Langmuir film balance. The experimental errors for both molecular area and surface pressure values are smaller than $5 \%$. The monolayer deposition process at the air/solution interface was carried out using a microsyringe. The protein solutions were prepared with the deionized water, but to improve the spreading process a $0.05 \%$ (v/v) solution of amyl alcohol was added in all cases [24].

Supersaturated solutions of calcium bicarbonate were prepared according to the procedures of Kitano [25]. Briefly, carbon dioxide gas was bubbled through a stirred aqueous suspension of $\mathrm{CaCO}_{3}$ for 24 hours. The suspension was then filtered and filtrate purged with $\mathrm{CO}_{2}$ gas for 0.5 hour to dissolve any remaining crystals. The resulting supersaturated solution had a $\mathrm{pH}$ of 5.8 6.0. Total $\mathrm{Ca}^{2+}$ concentrations $(2.5,5.0,7.5 \mathrm{mM}$ ) were measured using EDTA titration. The spreading monolayer at the air-water interface was formed by spreading solutions of BSA $(0.1 \mathrm{mM})$ on the pure water surface or supersaturated solutions of calcium bicarbonate. A 30-min lapse time was estimated to be sufficient to equilibrate the protein monolayer before compression. We used very low compression rates, ca. $3 \mathrm{~mm} / \mathrm{min}$, which have been shown to be appropriate to obtain reproducible BSA isotherms [26].

\subsection{Crystallization under Langmuir Monolayer}

The prepared supersaturated calcium bicarbonate solutions were poured into a Langmuir trough (KSV50003, maximum working area, $220 \mathrm{~cm}^{2}$ ), and the air-water interface was swept and aspirated before deposition of the surfactant solution. The surfactant solution $(10 \mu \mathrm{L})$ was carefully deposited onto the solution surface, and the monolayer was left for $30 \mathrm{~min}$ prior to compression. Pressure-Area isotherms were recorded while compressing the monolayer at rates of $3 \mathrm{~mm} / \mathrm{min}$ until surface pressures corresponding to a target pressure were reached $\left(15 \mathrm{mN} \cdot \mathrm{m}^{-1}\right)$. Each experiment was repeated three times with the same condition. Crystals as-grown in association with the monolayer were all removed after crystallization for $24 \mathrm{~h}$, by carefully horizontally dipping hydrophilic glass 
slides through the air-water interface. The crystal face growing into the solution is therefore directly deposited on the glass slide.

\subsection{Characterization of Crystal Phase and Morphology of $\mathrm{CaCO}_{3}$}

The sizes and morphologies of $\mathrm{CaCO}_{3}$ were characterized by using SEM on JSM-5600LV scanning electron microscopy (Jeol. Ltd. Japan) with operating at $30 \mathrm{kV}$. The slides supporting the crystals were mounted on copper sample stubs with conducting carbon tape and were sputter-coated with gold prior to viewing. The XRD measurements were made by X'Pero Pro X-ray diffractometer (Philips Ltd. Holand) at a scan rate of $0.040^{\circ} \mathrm{min}^{-1}$ with $\mathrm{Cu} \mathrm{K} \alpha_{1}$ radiation $(\lambda=1.5406 \AA)$. XRD was carried out at $40 \mathrm{kV}$ and $40 \mathrm{~mA}$.

\section{Results and Discussions}

\subsection{XRD Patterns}

XRD patterns of $\mathrm{CaCO}_{3}$ in different solute concentration were shown in Figure 1 . The results that the calcium carbonate formed is calcite phase which is orientated growth along the direction of (104) plane. We could find that the intensity of the diffraction peaks of the calcite was weak while the solute concentration is equal to $2.5 \mathrm{mM}$ as shown in Figure 1(a). From Figure 1(b), the diffraction peaks intensity of calcite became stronger gradually while the corresponding solute concentration is equal to $5.0 \mathrm{mM}$. When the solute concentration is equal to $7.5 \mathrm{mM}$, the reflection peak of (104) plane became stronger and its secondary reflection peak of (208) appears.

\subsection{SEM Images}

It was observed that various morphologies of $\mathrm{CaCO}_{3}$ could be formed when it is grown in BSA Langmuir monolayer at different solute concentration, as shown by the SEM images reproduced in Figure 2. Figure 2(a), Figure 2(b) showed SEM images of calcite particles obtained under the BSA Langmuir monolayer at the solute concentration $2.5 \mathrm{mM}$. It could be seen that the calcite took on a disk-like structure with an average of $0.75 \mu \mathrm{m}$ were produced. Figure $2(\mathrm{c})$ and Figure 2(d) are the SEM micrographs of calcite as-prepared when the solute concentration is equal to $5.0 \mathrm{mM}$. It could be seen that the $\mathrm{CaCO}_{3}$ particles took on bowknot-like morphology. The amplified image shows that the tip of the
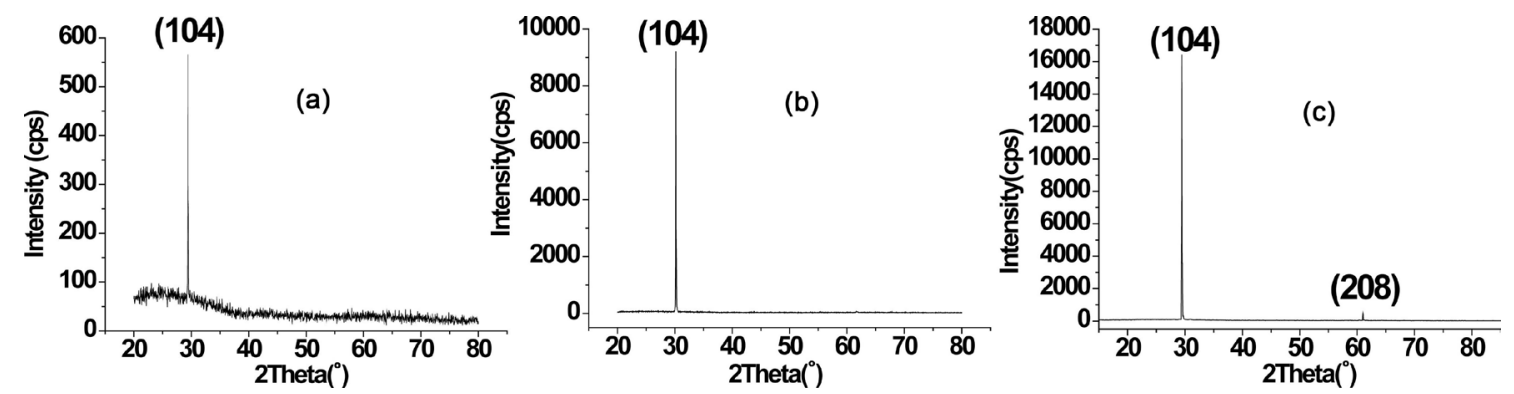

Figure 1. The XRD patterns f calcium carbonate at different solute concentration. (a) $2.5 \mathrm{mM}$, (b) $5.0 \mathrm{mM}$, (c) $7.5 \mathrm{mM}$. 

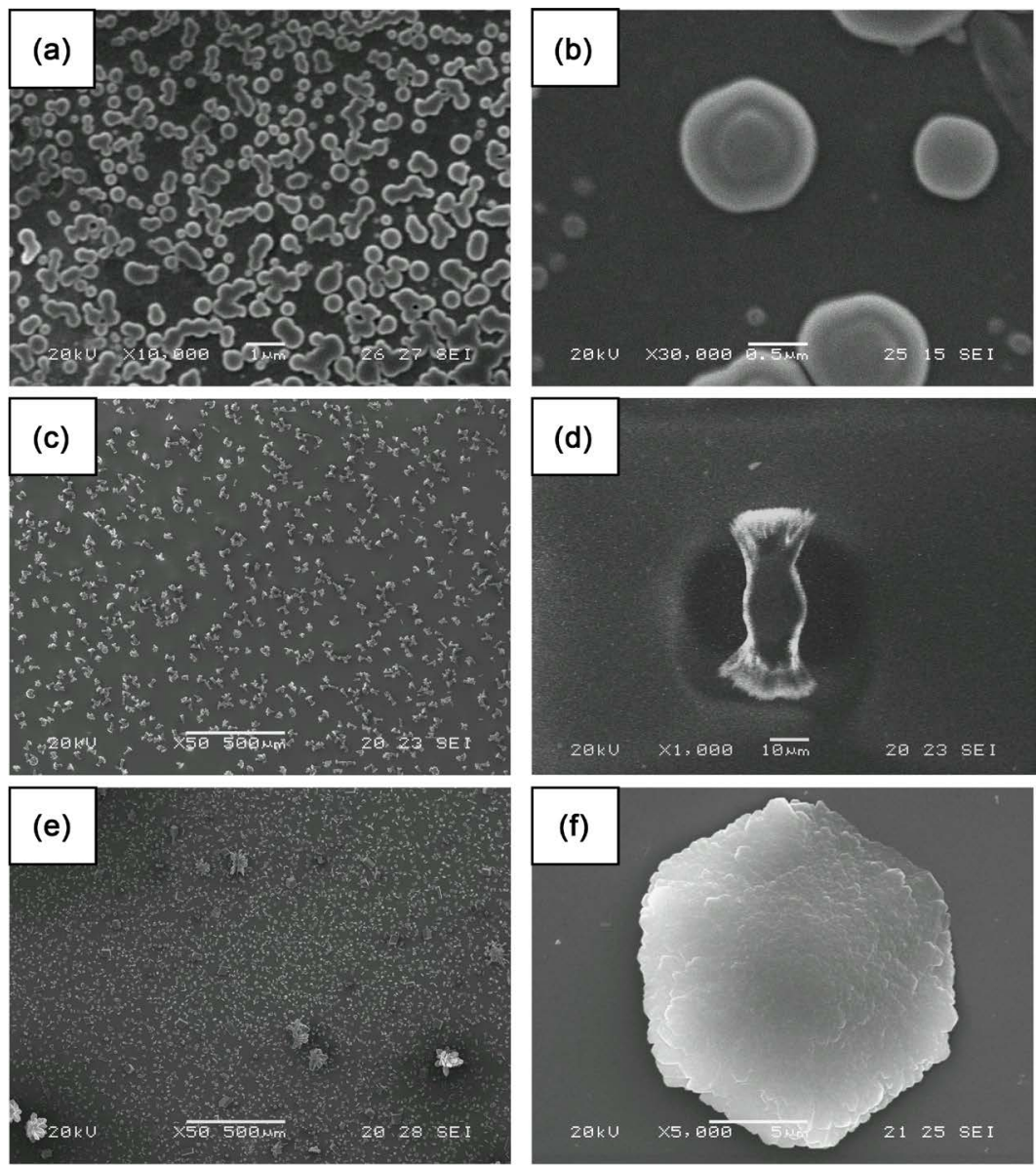

Figure 2. The SEM images of calcium carbonate at different solute concentration. ((a), (b)) $2.5 \mathrm{mM},((\mathrm{c}),(\mathrm{d})) 5.0 \mathrm{mM},((\mathrm{e}),(\mathrm{f})) 7.5 \mathrm{mM}$.

bowknot-like calcite is composed of needle-like crystals (as shown in Figure 2(d)).

Figure 2(e) and Figure 2(f) showed the morphologies of calcite particles produced underneath BSA Langmuir monolayer when the solute concentration is equal to $7.5 \mathrm{mM}$. It could be seen that the $\mathrm{CaCO}_{3}$ particles took on hexagonal plate morphology with an average length of $15 \mu \mathrm{m}$ and width of $20 \mu \mathrm{m}$, the amplified image showed that the boundary of bowknot-like calcite is composed of plate-like crystals. SEM images showed that a variety of morphology can be produced by changing the concentration of calcium carbonate.

Let us firstly look at the general nucleation process: the constituent molecules or ions in the solution may, on collision, join into groups of two or more particles to form dimers, trimers, tetramers, and so forth. Before the embryos can reach a critical radius, $r_{c}$, they are unstable even when a positive thermodynamic driving force $\Delta \mu$ is applied. To reach $r_{\mathrm{c}}$, an energy barrier, the so-called nucleation barrier, needs to be overcome. In which way and at which number the embryos reach the critical radius is the main concern. When the nucleation barrier is overcome, the second stage of the phase transition begins: growth. In the following section, the nucleation and growth will be discussed. 
A lot of documents believe that protein may recognize and bind to specific crystal faces, affecting nucleation, growth and morphology [27] [28]. According to the nucleation and growth theory [29] [30] [31], to form a new nucleus, the activation energy $\left(\Delta G_{N}\right)$ must be overcome. $\Delta G_{N}$ can be expressed as:

$$
\begin{gathered}
\Delta G_{N}=16 \pi\left(\Delta G_{1}\right)^{3} / 3(k T \ln S)^{2} \\
\Delta G_{B}=k T \ln S
\end{gathered}
$$

where $\Delta G_{1}$ is the surface energy that was needed to form the new interface and maintain the crystal growth, $\Delta G_{B}$ is the binding energy of crystal, $k$ is the Boltzmann constant, $T$ is the temperature, and $S$ is the supersaturation of area. The decrease of the surface energy $\Delta G_{1}$ or the increase of the $S$ can reduce the activation energy for crystal nucleation. The isoelectric points ( $\mathrm{pI}=4.7$ ) of BSA were both lower than the $\mathrm{pH}$ (7.0) of aqueous solution, the negative charges on the surface of BSA were surplus, they could attract $\mathrm{Ca}^{2+}$ strongly because of electrostatic interactions, it aroused the concentration of $\mathrm{Ca}^{2+}$ was rich in this region. At the same time, because the escape of $\mathrm{CO}_{2}$ from the interface of air-solution, which reduce the $\mathrm{pH}$ value of interface and consequently increase the degree of supersaturation at interface of air-solution [32], such conditions are advantageous to nucleate in general [33]; meanwhile BSA that offered nucleation sites for the growth of $\mathrm{CaCO}_{3}$ particles could reduce the surface energy, so $\Delta G_{N}$ declined, which was helpful for the formation of the most stable high-energy phase. From these results we could see that the presence of BSA Langmuir monolayer plays a very important role for the nucleation of $\mathrm{CaCO}_{3}$.

They may be important factors in controlling of $\mathrm{CaCO}_{3}$ growth and affect morphologies, such as $\mathrm{pH}$, templature, supersaturation etc. As the thermodynamic driving force, the supersaturation is the most decisive parameter for crystallization processes. It has a tremendous influence on mechanisms occurring during a crystallization process like: 1) Crystal growth; 2) Agglomeration and aggregation, and 3) Primary and secondary nucleation, all which will affect the morphology of crystals [34].

By compared with the morphology of calcium carbonate formed at different solute concentrations, the morphological difference at different concentrations may be due to the change of solute concentration and the presence of BSA Langmuir monolayer. However, the precise role of BSA Langmuir monolayer and solute concentration in the nucleation and growth process of the calcium carbonate remains enigmatic.

\section{Conclusion}

In summary, pure calcite particles with different morphologies were successfully prepared through biomimetic routes employing the supersaturated calcium carbonate solution under BSA Langmuir monolayer. The BSA Langmuir monolayer showed an obvious influence on the stages of nucleation and aggregation and crystal growth during the crystallization process of calcium carbonate. The con- 
centration of calcium carbonate solution obviously influenced the final morphology or aggregation mode of calcite crystals. The formation mechanisms of as well the hexagonal plates as flowerlike aggregates were proposed. This research could provide important information about the interaction between proteins matrix and crystallization of calcium carbonate which is useful to understand the mechanism of biomineralization.

\section{Funding}

Research initiation fund for high level talents introduction of Shanghai Publishing and Printing College, National Natural Science Foundation of China: Grant No. 21203055.

\section{Conflicts of Interest}

The authors declare no conflicts of interest regarding the publication of this paper.

\section{References}

[1] Donners, J.J.J., Nolte, R.J.M. and Sommerdijk, N.A.J.M. (2002) A Shape-Persistent Polymeric Crystallization Template for $\mathrm{CaCO}_{3}$. Journal of the American Chemical Society, 124, 9700-9701. https://doi.org/10.1021/ja0267573

[2] Fu, G., Valiyaveettil, S., Wopenka, B. and Morse, D.E. (2005) $\mathrm{CaCO}_{3}$ Biomineralization: Acidic 8-kDa Proteins Isolated from Aragonitic Abalone Shell Nacre Can Specifically Modify Calcite Crystal Morphology. Biomacromolecules, 6, 1289-1298. https://doi.org/10.1021/bm049314v

[3] Liang, P., Shen, Q., Zhao, Y., Zhou, Y., Wei, H., Lieberwirth, I., Huang, Y., Wang, D. and $\mathrm{Xu}, \mathrm{D}$. (2004) Petunia-Shaped Superstructures of $\mathrm{CaCO}_{3}$ Aggregates Modulated by Modified Chitosan. Langmuir, 20, 10444-10448. https://doi.org/10.1021/la0481602

[4] Macaskie, L.E., Yong, P., Paterson-Beedle, M., Thackray, A.C., Marquis, P.M., Sammons, R.L., Nott, K.P. and Hall, L.D. (2005) A Novel Non Line-of-Sight Method for Coating Hydroxyapatite onto the Surfaces of Support Materials by Biomineralization. Journal of Biotechnology, 118, 187-200. https://doi.org/10.1016/j.jbiotec.2005.03.006

[5] Kokubo, T. (2005) Design of Bioactive Bone Substitutes Based on Biomineralization Process. Materials Science and Engineering: C, 25, 97-104. https://doi.org/10.1016/j.msec.2005.01.002

[6] Fan, Y.W., Duan, K. and Wang, R.Z. (2005) A Composite Coating by Electrolysis-Induced Collagen Self-Assembly and Calcium Phosphate Mineralization. Biomaterials, 26, 1623-1632. https://doi.org/10.1016/j.biomaterials.2004.06.019

[7] Nancollas, G.H. and Wu, W. (2000) Biomineralization Mechanisms: A Kinetics and Interfacial Energy Approach. Journal of Crystal Growth, 211, 137-142. https://doi.org/10.1016/S0022-0248(99)00816-7

[8] Eiden-Aßmann, S., Viertelhaus, M., Heiß, A., Hoetzer, K.A. and Felsche, J. (2002) The Influence of Amino Acids on the Biomineralization of Hydroxyapatite in Gelatin. Journal of Inorganic Biochemistry, 91, 481-486.

https://doi.org/10.1016/S0162-0134(02)00481-6 
[9] Falini, G., Gazzano, M. and Ripamonti, A. (1996) Magnesium Calcite Crystallizatin from Water-Alcohol Mixtures. Chemical Communications, 9, 1037-1038. https://doi.org/10.1039/CC9960001037

[10] Xie, A.J., Yuan, Z.W. and Shen, Y.H. (2005) Biomimetic Morphogenesis of Calcium Carbonate in the Presence of a New Amino-Carboxyl-Chelating-Agent. Journal of Crystal Growth, 276, 265-274. https://doi.org/10.1016/j.jcrysgro.2004.11.376

[11] Nebel, H. and Epple, M. (2008) Continuous Preparation of Calcite, Aragonite and Vaterite, and of Magnesium-Substituted Amorphous Calcium Carbonate (Mg-ACC). Zeitschrift für anorganische Chemie, 634, 1439-1443. https://doi.org/10.1002/zaac.200800134

[12] Han, Y.J. and Aizenberg, J. (2003) Effect of Magnesium Ions on Oriented Growth of Calcite on Carboxylic Acid Functionalized Self-Assembled Monolayer. Journal of the American Chemical Society, 125, 4032-4033. https://doi.org/10.1021/ja034094z

[13] Wong, K.K.W. and Mann, S. (1998) Small Scale Structures in Biomineralization and Biomimetic Materials Chemistry. Current Opinion in Colloid \& Interface Science, 3, 63-68. https://doi.org/10.1016/S1359-0294(98)80043-5

[14] Han, Y.J. and Aizenberg, J. (2003) Effect of Magnesium Ions on Oriented Growth of Calcite on Carboxylic Acid Functionalized Self-Assembled Monolayer. Journal of the American Chemical Society, 125, 4032-4033. https://doi.org/10.1021/ja034094z

[15] Davis, K.J., Dove, P.M. and De Yoreo, J.J. (2000) The Role of $\mathrm{Mg}^{2+}$ as an Impurity in Calcite Growth. Science, 290, 1134. https://doi.org/10.1126/science.290.5494.1134

[16] Wada, N., Yamashita, K. and Umegaki, T. (1999) Effects of Carboxylic Acids on Calcite Formation in the Presence of $\mathrm{Mg}^{2+}$ Ions. Journal of Colloid and Interface Science, 212, 357-364. https://doi.org/10.1006/jcis.1998.6067

[17] Jiao, Y.F., Feng, Q.L. and Li, X.M. (2006) The Co-Effect of Collagen and Magnesium Ions on Calcium Carbonate Biomineralization. Materials Science and Engineering. $C, 26,648-652$. https://doi.org/10.1016/j.msec.2005.08.038

[18] Xie, A.J., Shen, Y.H., Li, X.Y., Yuan, Z.W., Qiu, L.G., Zhang, C.Y. and Yang, Y.F. (2007) The Role of $\mathrm{Mg}^{2+}$ and $\mathrm{Mg}^{2+} /$ Amino Acid in Controlling Polymorph and Morphology of Calcium Carbonate Crystal. Materials Chemistry and Physics, 101, 87-92. https://doi.org/10.1016/j.matchemphys.2006.02.019

[19] Zhu, L.Y., Zhao, Q.R., Zheng, X.W. and Xie, Y.J. (2006) Formation of Star-Shaped Calcite Crystals with $\mathrm{Mg}^{2+}$ Inorganic Mineralizer without Organic Template. Journal of Solid State Chemistry, 179, 1247-1252. https://doi.org/10.1016/j.jssc.2006.01.036

[20] Gong, H.F., Yang, Y., Pluntke, M., Marti, O., Majer, Z., Sewald, N. and Volkmer, D. (2014) Calcium Carbonate Crystal Growth Beneath Langmuir Monolayers of Acidic $\beta$-Hairpin Peptides. Dalton Transactions, 43, 16857-16871. https://doi.org/10.1039/C4DT01154F

[21] Falini, G., Albeck, S., Weiner, S. and Addadi, L. (1996) Control of Aragonite or Calcite Polymorphism by Mollusk Shell Macromolecules. Science, 271, 67-69. https://doi.org/10.1126/science.271.5245.67

[22] Falini, G., Gazzano, M. and Ripamonti, A. (1994) Crystallization of Calcium Carbonate in Presence of Magnesium and Polyelectrolytes. Journal of Crystal Growth, 137, 577-584. https://doi.org/10.1016/0022-0248(94)91001-4

[23] Sugawara, A. and Kato, T. (2000) Aragonite $\mathrm{CaCO}_{3}$ Thin-Film Formation by Cooperation of $\mathrm{Mg}^{2+}$ and Organic Polymer Matrices. Chemical Communications, No. 6, 487-488. https://doi.org/10.1039/a909566g 
[24] Meldruma, F.C. and Hyde, S.T. (2001) Morphological Influence of Magnesium and Organic Additives on the Precipitation of Calcite. Journal of Crystal Growth, 231, 544-558. https://doi.org/10.1016/S0022-0248(01)01519-6

[25] Kitano, Y. (1962) The Behavior of Various Inorganic Ions in the Separation of Calcium Carbonate from a Bicarbonate Solution. Bulletin of the Chemical Society of Japan, 35, 1973-1980. https://doi.org/10.1246/bcsj.35.1973

[26] Noyes, R.M. (1962) Thermodynamics of Ion Hydration as a Measure of Effective Dielectric Properties of Water. Journal of the American Chemical Society, 84, 513-522. https://doi.org/10.1021/ja00863a002

[27] Sánchez-González, J., Ruiz-García, J. and Gálvez-Ruiz, M.J. (2003) Langmuir-Blodgett Films of Biopolymers: A Method to Obtain Protein Multilayers. Journal of Colloid and Interface Science, 267, 286-293. https://doi.org/10.1016/S0021-9797(03)00754-9

[28] Mann, S., Heywood, B.R., Rajam, S. and Birchall, J.D. (1988) Controlled Crystallization of $\mathrm{CaCO}_{3}$ under Stearic Acid Monolayers. Nature (London), 334, 692-695. https://doi.org/10.1038/334692a0

[29] Xue, Z.H., Hu, B.B., Dai, S.X. and Du, Z.L. (2012) Crystallization and Self-Assembly of Flowerlike Superstructures of Calcium Carbonate Regulated by Pepsin Langmuir Monolayers. Materials Chemistry and Physics, 136, 771-777. https://doi.org/10.1016/j.matchemphys.2012.07.054

[30] Yu, J.G., Tang, H., Cheng, B. and Zhao, X.J. (2004) Morphological Control of Calcium Oxalate Particles in the Presence of Poly-(styrene-alt-maleic acid). Journal of Solid State Chemistry, 177, 3368-3374. https://doi.org/10.1016/j.jssc.2004.06.007

[31] Zhang, D.B., Qi, L.M., Ma, J.M. and Cheng, H.M. (2002) Morphological Control of Calcium Oxalate Dihydrate by a Double-Hydrophilic Block Copolymer. Chemistry of Materials, 14, 2450-2457. https://doi.org/10.1021/cm010768y

[32] Xue, Z.H., Hu, B.B., Dai, S.X. and Du, Z.L. (2015) Transformation of Amorphous Calcium Carbonate to Rod-Like Single Crystal Calcite via "Copying" Collagen Template. Materials Science and Engineering: C, 55, 506-511. https://doi.org/10.1016/j.msec.2015.05.079

[33] Fernandez-Diaz, L., Putnis, A., Prieto, M. and Putnis, C.V. (1996) The Role of Magnesium in the Crystallization of Calcite and Aragonite in a Porous Medium. Journal of Sedimentary Research, 66, 482-491. https://doi.org/10.1306/D4268388-2B26-11D7-8648000102C1865D

[34] Raz, S., Hamilton, P.C., Wilt, F.H., Weiner, S. and Addadi, L. (2003) The Transient Phase of Amorphous Calcium Carbonate in Sea Urchin Larval Spicules: The Involvement of Proteins and Magnesium Ions in Its Formation and Stabilization. $A d-$ vanced Functional Materials, 13, 480-486. https://doi.org/10.1002/adfm.200304285

[35] Liu, X.Y. and Lim, S.W. (2003) Templating and Supersaturation-Driven Anti-Templating: Principles of Biomineral Architecture. Journal of the American Chemical Society, 125, 888-895. https://doi.org/10.1021/ja020355d 